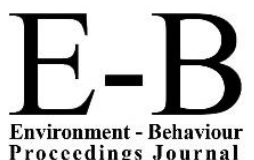

Environment - Behaviour
AIVCE-BS-2, 2020ShahAlam

https://www.amerabra.org; https://fspu.uitm.edu.my/cebs; https://www.emasemasresources.com/ AMEABRA International Virtual Conference on Environment-Bahaviour Studies, ${ }^{\text {nd }}$ Series CE-Bs, FSPU, Universiti Teknologi MARA, Shah Alam, 02-03 Dec 2020

\section{e-IPH}

e-International Publishing House Ltd United Kingdom

\title{
A Survey on the Evidence-Based Practice of Optometrists in Malaysia
}

\author{
Elly Liyana Zainodin, Nur Dzakirah Jantan \\ Centre of Optometry, Faculty of Health Sciences, \\ Universiti Teknologi MARA Cawangan Selangor, Kampus Puncak Alam, 42300 Selangor, Malaysia. \\ ellyzainodin@gmail.com, kiadz2897@gmail.com \\ Tel: 0149678687
}

\begin{abstract}
Evidence-based practice is useful to help healthcare practitioners, including optometrists, to give the best level of patient care. To date, little is known about the form of evidence used by optometrists in Malaysia in their clinical decision-making. A cross-sectional survey that explores the implementation of evidence-based practice was completed online by 137 registered optometrists. Overall, findings indicate that the respondents did not sufficiently apply evidence-based practice in clinical. Time constraints and restriction in access hinder the respondents from reading journals regularly. The evidence-based practice needs to be formally nurtured in optometry education to bridge the gap between research and clinical.
\end{abstract}

Keywords: evidence-based practice; optometry; clinical

eISSN: 2398-42870 2020. The Authors. Published for AMER ABRA cE-Bs by e-International Publishing House, Ltd., UK. This is an open access article under the CC BYNC-ND license (http://creativecommons.org/licenses/by-nc-nd/4.0). Peer-review under responsibility of AMER (Association of Malaysian Environment-Behaviour Researchers), ABRA (Association of Behavioural Researchers on Asians) and cE-Bs (Centre for Environment-Behaviour Studies), Faculty of Architecture, Planning \& Surveying, Universiti Teknologi MARA, Malaysia.

DOI: https://doi.org/10.21834/ebpj.v5i15.2502.

\subsection{Introduction}

Health care professionals traditionally make clinical decisions based on information they obtained from patients and their family members and through clinical experience in the workplace. A more structured approach has been established and widely recognized in medicine and other allied health sectors known as evidence-based practice (EBP). The term evidence-based practice derives from evidencebased medicine (EBM) aims to transform health care practitioner's clinical decision-making thinking from solely based on intuition and unsystematic clinical experience towards the integration of scientific and clinically relevant research (Rogers, 2012).

The principle of evidence-based practice integrates three components namely the current high-quality scientific evidence, the clinical expertise and experience of practitioners, and the patient's preferences and values to help clinicians make sound clinical decisions for optimal patient outcomes (Straus, Glasziou, Richardson, \& Haynes, 2019). To incorporate evidence-based practice, healthcare professionals need to undertake five steps. This process begins with formulating a clinical question to identify a problem, followed by searching the best evidence to answer the clinical question, critically appraise the evidence, applying appraised evidence, and the final step is evaluating the effectiveness of outcomes (Hoffmann, Bennett, \& Del Mar, 2017).

\subsection{Literature Review}

The use of the evidence-based practice is regarded as necessary in various fields of healthcare, including optometry, where optometrists assume growing responsibilities in primary eye care. However, the main concern for EBP is its implementation into clinical practice. In the field of optometry, previous surveys have shown a lack of EBP implementation on the management of pediatric myopia (Douglass, Keller, He, \& Downie, 2020) and dry eye patients (Downie, Keller, \& Vingrys, 2013) despite optometrists' awareness of the emerging

eISSN: 2398-42870 2020. The Authors. Published for AMER ABRA cE-Bs by e-International Publishing House, Ltd., UK. This is an open access article under the CC BYNC-ND license (http://creativecommons.org/licenses/by-nc-nd/4.0/). Peer-review under responsibility of AMER (Association of Malaysian Environment-Behaviour Researchers), ABRA (Association of Behavioural Researchers on Asians) and cE-Bs (Centre for Environment-Behaviour Studies), Faculty of Architecture, Planning \& Surveying, Universiti Teknologi MARA, Malaysia.

DOI: https://doi.org/10.21834/ebpj.v5i15.2502. 
evidence in those areas. Previous studies investigating the form of evidence used by optometrists in clinical decision-making indicate that optometrists did not sufficiently utilize current and best evidence available to make their clinical decisions (Alnahedh, Suttle, Alabdelmoneam, \& Jalbert, 2015; Osuagwu, Almaliki, \& Alanazi, 2019; Suttle, Jalbert, \& Alnahedh, 2012). Using a combination of lowand high-level evidence to underpin their clinical decisions, optometrists were also reportedly had no in-depth knowledge of the EBP process to implement evidence-based practice (Alnahedh et al., 2015)

The results provided by these studies raise questions about the clinical decision-making process by optometrists in Malaysia. Due to the increasing responsibilities borne by optometrists in primary eye care, it is therefore imperative to address this question. The present study aims to explore the use of EBP among optometrists in Malaysia and further assess its association with practitioner's profile. The information obtained from this research allows the researchers and educators in optometry to have a better understanding of the current method and strategies used by the optometrists in the country, and the challenges they face in achieving the best clinical results for their patients.

\subsection{Methodology}

\subsection{Materials of the study}

This cross-sectional study evaluated the evidence-based practice of optometrists in Malaysia using a questionnaire. The questionnaire adopted from the previous study by Suttle et al., (2012)has been modified, with a few questions about demographics added. The original set of the questionnaire in English was translated into the Malay language to suit the targeted respondents. The draft questionnaire in both English and Malay language was pilot-tested on ten optometrists who were not included as study respondents to ensure clarity of the questions and was accordingly revised. The final 19-item questionnaire was created online using the Google Form to collect demographic information (gender, age, work status), the form of evidence the respondents used to support their clinical decisions, the journals they read and continuous education they have undertaken.

\subsection{Procedures}

The Malaysian Optical Council was contacted with a request for registered optometrists contact information. With the contact information provided, the dissemination of online questionnaires to a total of 297 optometrists was done via email and through Whatsapp application containing an invitation link to the online survey between April and June 2020. Consent for the optometrist participation was assumed with the completion of the survey. Ethics approval was obtained from the UiTM Research Ethics Committee.

\subsection{Data Analysis}

Statistical analysis using the SPSS statistical software program (SPSS 21.0) was performed. Descriptive analysis was reported, and the Chi-squared test was done at $\alpha=0.05$ significance level to assess the association between the duration of working experience with the number of hours spent on continuous education and the source of information used to modify clinical practice.

\subsection{Findings}

\subsection{Demographic}

One hundred and thirty-seven registered optometrists completed the questionnaire, giving a response rate of $46 \%$. The majority of the respondents were female (86.1\%), age between 23 to 27 years old. Most of the surveyed optometrists work in private practice (38.7\%), followed by chain practice $(37.2 \%)$, hospitals $(21.9 \%)$, and university $(2.2 \%)$. A majority of the respondents were optometrists working full time (93.4\%), and almost all graduated from UiTM (98.5\%). A majority of the respondents graduated less than ten years (93.4\%) in optometry, and mostly with less than five years of working experience as an optometrist (62.8\%). Table 1 summarized the demographics. In this study, the majority of respondents were currently working in Selangor $(27 \%)$, followed by Wilayah Persekutuan Kuala Lumpur (10.2\%) and Perak (9.5\%).

Table 1. Demographic data

\begin{tabular}{lcc}
\multicolumn{2}{c}{ Table 1. Demographic data } \\
\hline Gender & Frequency ( $\mathbf{n})$ & Percentage (\%) \\
Male & 19 & 13.9 \\
Female & 118 & 86.1 \\
\hline Age & & \\
$23-27$ & 69 & 50.4 \\
$28-32$ & 55 & 40.1 \\
$33-37$ & 12 & 8.8 \\
$>37$ & 1 & 0.7 \\
\hline Type of Optometry Practice & & \\
Chain & 51 & 37.2 \\
Private practice & 53 & 38.7 \\
University & 3 & 2.2 \\
Private hospital & 6 & 4.4 \\
Government hospital & & \\
\hline
\end{tabular}




\begin{tabular}{|c|c|c|}
\hline & 24 & 17.5 \\
\hline \multicolumn{3}{|l|}{ Work Status } \\
\hline Full-time & 128 & 93.4 \\
\hline Part-time & 2 & 1.5 \\
\hline Self-employed & 5 & 3.6 \\
\hline Unemployed & 2 & 1.5 \\
\hline \multicolumn{3}{|c|}{ University Graduated } \\
\hline UiTM & 135 & 98.5 \\
\hline UKM & 1 & 0.7 \\
\hline MSU & 1 & 0.7 \\
\hline \multicolumn{3}{|l|}{ Graduated Year } \\
\hline$<10$ & 128 & 93.4 \\
\hline$>10$ & 9 & 6.6 \\
\hline \multicolumn{3}{|c|}{ Years Practicing as Optometrists } \\
\hline$<5$ & 86 & 62.8 \\
\hline $5-10$ & 43 & 31.4 \\
\hline$>10$ & 8 & 5.8 \\
\hline
\end{tabular}

4.2. Source of information that supports clinical decision

The respondents then selected the sources of information that support their decisions in clinical practice (Refer to Figure 1). Patient's history based on signs and symptoms (16.1\%), advice and information from colleagues $(13.5 \%)$ and information gained during the undergraduate study $(12.9 \%)$ were selected as the most used sources to support their clinical decisions. Other sources such as professional mailing lists or discussion boards (3.9\%), specialist internet sites $(5.2 \%)$, and official documents from government departments or professional body (5.7\%) were the least used. Only $35.8 \%$ of the respondents indicated that they had modified their practice accordingly in the past two years based on the presence of new information. The sources of information that attribute the changes in their practice were the new information gained from continuous education (CE) seminars (18.3\%) and a colleague's advice (16.8\%) (Figure 2). The respondents described that the changes involved clinical assessment, such as refraction and patient treatment related to binocular vision, low vision, vision therapy, and myopia control.

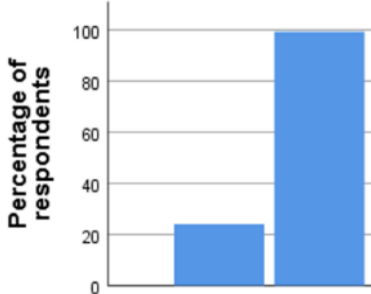

(1)

(2)
(3)

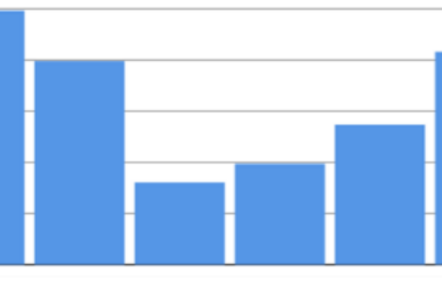

(4)
(5)
(6)

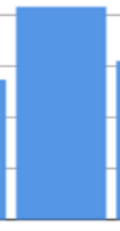

(7)

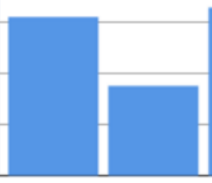

(8)
(9)

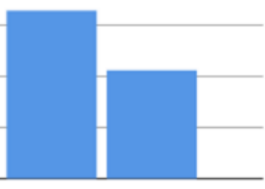

(10) (11)

Source of information

(1) Professional mailing lists/discussion boards

(2) Patient's signs, history and symptoms

(3) Knowledge and information gained in the undergraduate optometric study

(4) Specialist internet sites

(5) Knowledge and information gained in the post-graduated optometric study

(6) Knowledge and information gained from reading journals

(7) Advice and information from colleagues

(8) The product information provided by optical and/or pharmaceutical companies

(9) Official documents from government departments or professional associations

(10) Internet search

(11) A literature search using internet database

Fig 1. The percentage of respondents according to a range of sources of information used to underpin clinical decisions 


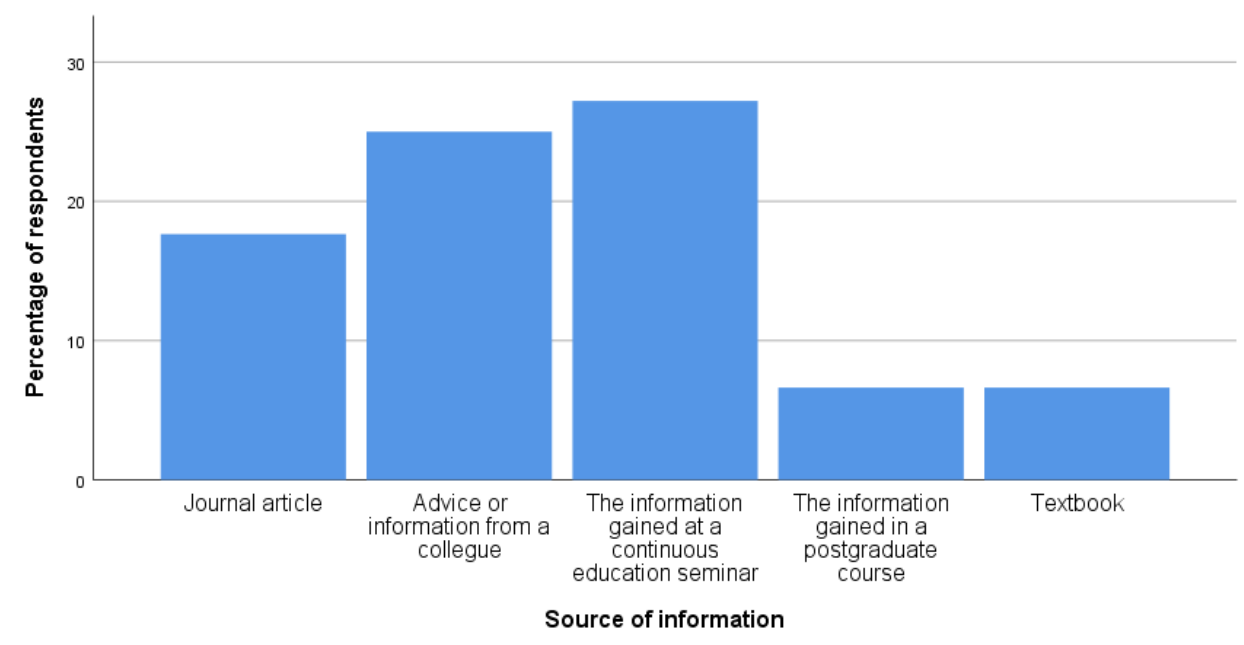

Fig 2. Percentage of respondents who had based a change in their practice on various source of information

\subsection{Continuous education}

Slightly more than half of the respondents (51.8\%) indicated that they spent less than 10 hours of continuous education last year, and the trend of distribution decreases with increasing hours of continuous education (Figure 3). The primary source of continuous education cited by almost half of the respondents $(47.9 \%)$ was conferences. A further $20 \%$ indicated that product training or sharing session as their main source of continuous education, followed by $19.3 \%$ indicated seminar series organized by the Malaysian Association of Optometrist.

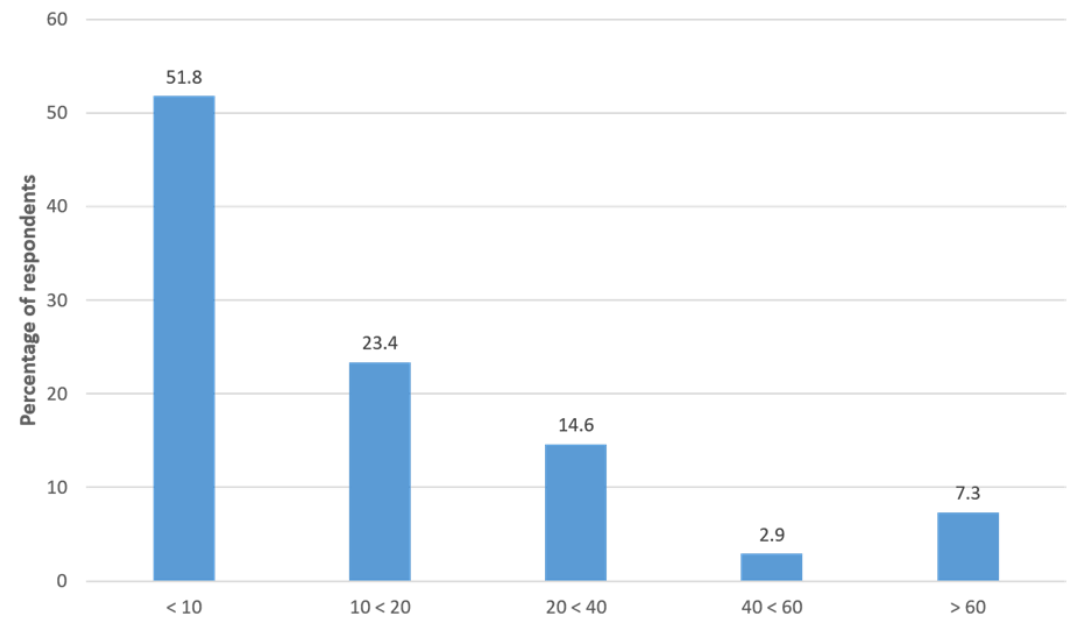

Fig 3 Percentage of respondents who spent a range of hours in continuing education (CE)

\subsection{Habits of reading journals}

The respondents were asked to indicate how frequently they read journals and the types of the journal they read. Based on the analysis (Figure 4), $29 \%$ of the respondents did not read scientific journals regularly. Those who read journals indicated that they regularly read Optometry and Vision Science (28\%), and Clinical and Experimental Optometry (27\%) at least once a month. For $71 \%$ of respondents who stated they often read journals, only $2.9 \%$ read the journals more than once a week, and $8.8 \%$ read once a week while the rest rarely read. The study surveyed factors that hinder the respondents from reading journals regularly. Time limitation (45.3\%) and restrictions in journal access (24.7\%) were the two most contributing factors reported by the respondents. Other reasons were the journals were not easily understandable (16.1\%), and that the journals were not sufficiently related to their clinical practice $(12.1 \%)$. There were four respondents stated that they are not interested in new intervention and that it is difficult to find new information or reference for a particular case as the factor that hinders them from reading journals. 


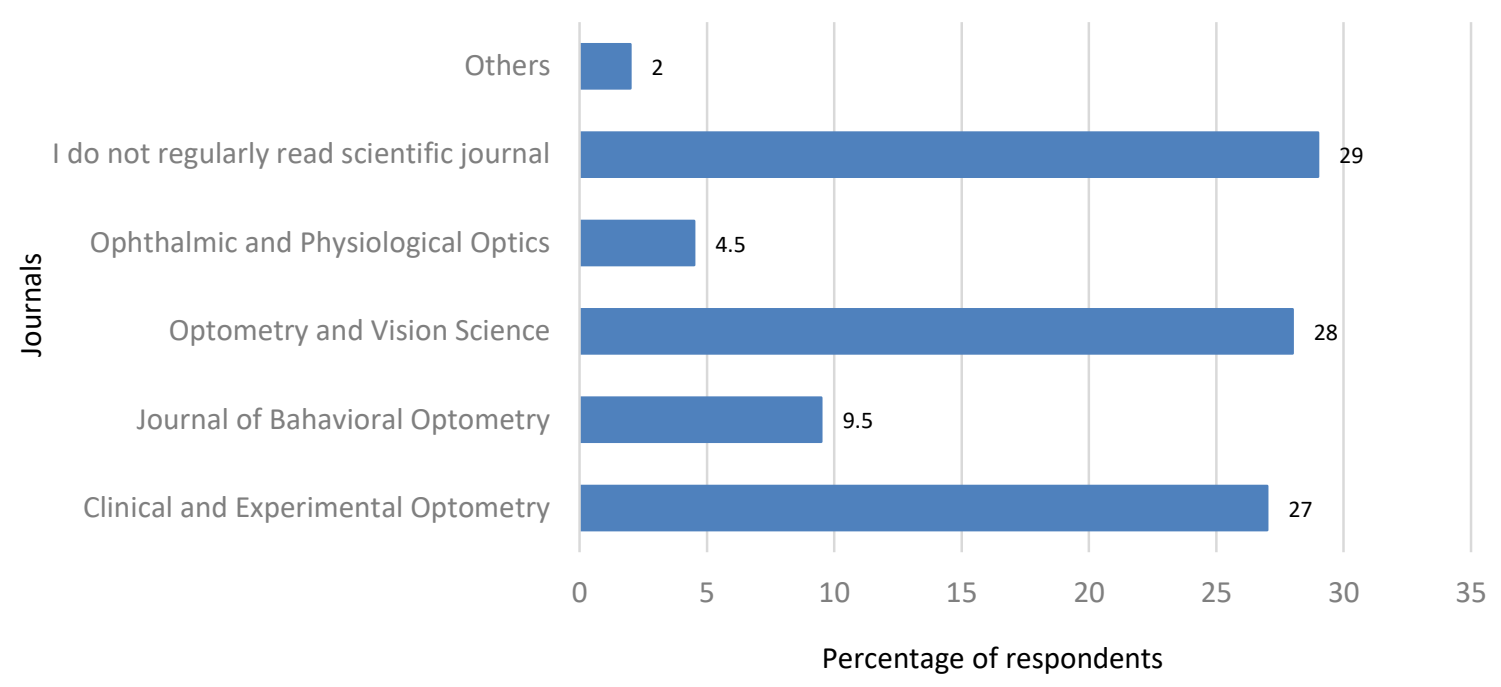

Fig 4 Percentage of respondents indicating a range of journals they read regularly

\subsection{Association between practitioners' working experience with the number of hours spent for clinical education and the source used to modify practice}

Assessment of the association with practitioner's characteristics with Pearson Chi-Squared test revealed that the number of years the respondents had been practising was significantly associated with the source of information that they based the change in their clinical practice $(p=0.032)$. A significant association was also observed between the number of years the respondents had been practising and the number of hours spent for clinical education in the previous year $(p=0.008)$. Specifically, practitioners with longer years of clinical experience spent a higher number of hours in continuing education, and they were more likely to use information from journal articles, information from a colleague, and continuous education equally as a basis for a change in their practice (Figure 5). Only four respondents gave their comments on evidence-based practice (EBP). Of the four feedbacks, one was regarded as positive, indicating that EBP helps in improving clinical practice by considering the patient's complaint. The rest provided negative feedbacks, indicating that EBP has not been applied thoroughly in Malaysia, especially in chain optometry practice and that it needs more time and reference.

A

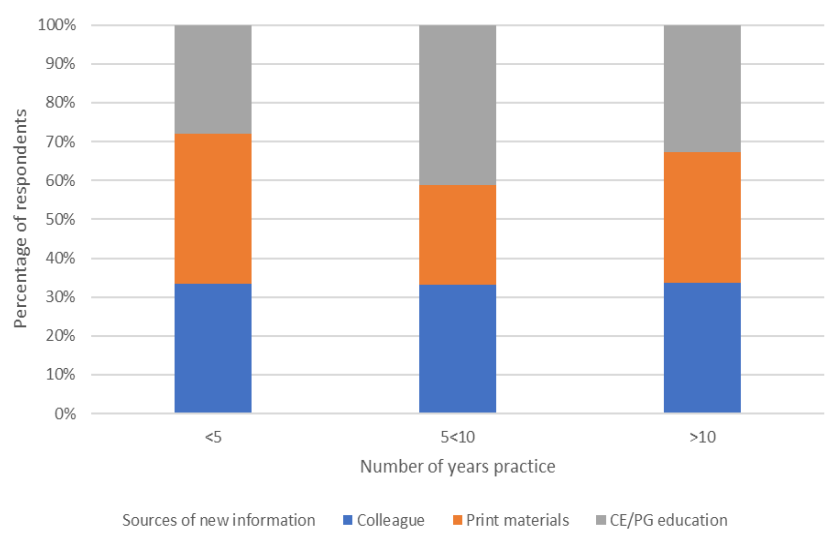

B

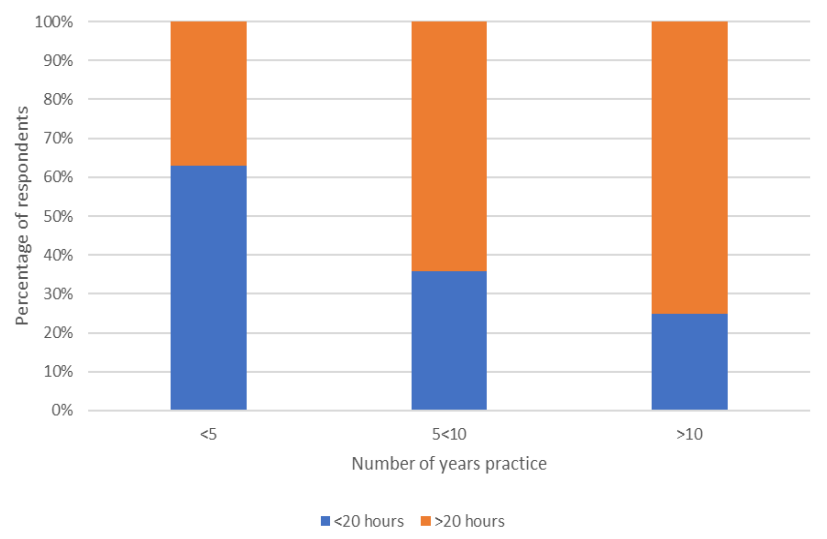

Fig 5 (A) Percentage of respondents who based a change in their clinical practice on continuing (CE) or postgraduate (PG) education, information obtained from print materials (journal articles or textbooks) or advice from colleagues for each category of numbers of years spent in practice; (B) percentage of respondents who spent less than 20 hours or more than 20 hours in CE for each category of numbers of years spent in practice

\subsection{Discussion}

This survey aimed to investigate the form of evidence used by optometrists in Malaysia when making clinical decisions. Of the 11 listed sources of information that possibly used to support clinical decisions, respondents were found to rely on the patient's signs and symptoms the most. This finding is consistent with previous studies of Suttle et al., (2012) and Osuagwu et al., (2019) owing to the clinician's dependence on patient's history and symptoms along with findings of other aspects of examination that are key to formulate clinical diagnosis in optometry practice (Vanderbilt et al., 2016; Wilson, Henderson, \& Gerald, 2012). 
The second most used source of information in the present study, which additionally attributed to the modification in their practice was advice and information from colleagues. This finding is different from previous studies where the respondents regarded this factor as a less important source (Osuagwu et al., 2019; Suttle et al., 2012). In this study, experienced practitioners of more than ten years were more likely to use information from clinical education, journal articles and information from colleagues equally to change their clinical-decision while those with lesser years of clinical experience (less than ten years) were more likely to refer to printed material such as textbooks as the evidence for changing their clinical decisions. With a diverse range of evidence, experienced practitioners provide not only safe and high-quality care to their patients, but also facilitates effective clinical decision making and support for their colleagues (Benner, Hughes, \& Sutphen, 2008; Hoffman, Donoghue, \& Duffield, 2004).

The third factor indicated is knowledge obtained from undergraduate study. These findings show that the respondents resorted to their colleagues and greatly depending on their former knowledge as the basis of their clinical decisions rather than independently outsource the new and current scientific evidence. It is therefore not surprising that about two-thirds of the respondents in this study reported that they did not make changes to their clinical practice in the last two years because in the absence of new information they would not consider it necessary. However, it is worth to note that similar to the study by Suttle et al., (2012), information from continuing education was reported as the primary source for the basis of change for the remaining respondents who modified their practice.

In Malaysia, the Continuing Professional Developments (CPD) program introduced by the Ministry of Health was enhanced in 2017, where the program will not only cater to optometrists in hospitals, but also to private optometry practitioners to support their lifelong learning. This step is seen as important as the program enhances continuing education from being teacher-driven to learner-driven with latest research and discoveries to improve their knowledge and professionalism (Institute of Medicine (US) Committee on Planning a Continuing Health Professional, 2010). Nevertheless, a majority of the respondents spent only the minimum hours of continuing education last year, which is less than 10 hours. The time spent was much lower compared to the study in Saudi Arabia and Australia and New Zealand, where the majority of optometrists spent at least 20 to 40 hours of continuing education (Osuagwu et al., 2019; Suttle et al., 2012). A possible explanation for the discrepancy is that the regulation board, Malaysia Optical Council has not enforced the use of CPD credit points for the renewal of annual practising license for optometrists in Malaysia at the time of the survey. In countries like Australia and New Zealand, and Saudi Arabia, a minimum number of hours of continuing education was set for the optometrists thus explains the higher hours spent on continuous education.

Another important finding was that most of the respondents in this survey $(29 \%)$ did not regularly read journals, a rate higher than the study reported among optometrists in Australia and New Zealand (Suttle et al., 2012) but lower than the study among optometrists in Saudi Arabia (Osuagwu et al., 2019). In the study among the optometrists in Australia and New Zealand, a majority of the respondents (87\%) reportedly read Clinical and Experimental Optometry journal with 69\% held membership. Therefore, it may not be a problem for the vast majority of their respondents to access the journal compared to the current study respondents where access to the journal is a major barrier (Alnahedh et al., 2015). Either individual subscription or payment probably overcomes the barrier in accessing the journal among the respondents in this survey who reportedly read the journal or they possibly rely on the limited open access. However, it is not conclusive as the current study did not survey the respondents' membership with any professional body that may have offer access to some of the listed journals.

Time constraint was reported by the respondents as another barrier to reading the journals periodically. Suttle et al., (2012) suggested reading systematic reviews available from the Cochrane library, which contains a collection of databases of different types of high-quality evidence to help assist in healthcare decision-making. While this may offer some solutions to the optometrists, they must learn to be critical in reading and analysing the various forms of evidence in journal articles when there are no systematic reviews.

The limitation of this survey is the small sample size, and result does not represent a wider optometrist population working in different demographics background as the majority of respondents were young optometrists working in the state of Selangor. Almost all respondents graduated from Universiti Teknologi MARA, with only one representative from each Universiti Kebangsaan Malaysia and Management and Science University respectively.

\subsection{Conclusion\& Recommendations}

To our knowledge, this survey is the first to determine evidence-based practice (EBP) among optometrists in Malaysia by exploring the form of evidence they use as the basis for their clinical decision-making. The respondents place lesser weight on scientific evidence when making clinical decisions that integrate into practice suggesting lack of EBP implementation among the optometrists. This survey recommends that future studies investigate practitioners' understanding of the requirements and process involved in evidence-based practice. Such information may help determine the direction for continuing education and help guide educational institutions to reform the optometry program.

\section{Acknowledgements}

We want to thank Malaysian Optical Council and all respondents who had participated in this survey.

\section{Paper Contribution to Related Field of Study}

This paper contributes to the field of optometry education in Malaysia by providing some perspectives on the optometrists' practice of 
lifelong learning after graduation. Ultimately, university educators, relevant optometry organisations and associations must find ways together in the future to develop strategies to remove barriers in evidence-based practice to strengthen and support a culture of evidencebased practice among optometrists proactively.

\section{References}

Alnahedh, T., Suttle, C. M., Alabdelmoneam, M., \& Jalbert, I. (2015). Optometrists show rudimentary understanding of evidence-based practice but are ready to embrace it: can barriers be overcome? Clinical and Experimental Optometry, 98(3), 263-272. https://doi.org/10.1111/cxo.12238

Benner, P., Hughes, R. ., \& Sutphen, M. (2008). Clinical Reasoning, Decisionmaking, and Action: Thinking Critically and Clinically. In H. RG (Ed.), Patient Safety and Quality: An Evidence-Based Handbook for Nurses. https://doi.org/https://www.ncbi.nlm.nih.gov/books/NBK2643/

Douglass, A., Keller, P. R., He, M., \& Downie, L. E. (2020). Knowledge, perspectives and clinical practices of Australian optometrists in relation to childhood myopia. Clinical and Experimental Optometry, 103(2), 155-166. https://doi.org/10.1111/cxo.12936

Downie, L. E., Keller, P. R., \& Vingrys, A. J. (2013). An Evidence-Based Analysis of Australian Optometrists' Dry Eye Practices. Optometry and Vision Science, 90(12). Retrieved from https://journals.Iww.com/optvissci/Fulltext/2013/12000/An_Evidence_Based_Analysis_of_Australian.8.aspx

Hoffman, K., Donoghue, J., \& Duffield, C. (2004). Decision-making in clinical nursing: investigating contributing factors. Journal of Advanced Nursing, 45(1), 53-62. https://doi.org/10.1046/j.1365-2648.2003.02860.x

Hoffmann, T., Bennett, S., \& Del Mar, C. (2017). Evidence-Based Practice Across the Health Professions (3rd ed.). Retrieved from https://books.google.com.my/books?id=yGcIDwAAQBAJ\&lpg=PP1\&ots=X-Wzg7TGBm\&dq=evidence based practice\%2C health\&lr\&pg=PR4\#v=onepage\&q=evidence based practice, health\&f=false

Institute of Medicine (US) Committee on Planning a Continuing Health Professional. (2010). Continuing Professional Development: Building and Sustaining a Quality Workforce. In Redesigning Continuing Education in the Health Professions. https://doi.org/https://www.ncbi.nlm.nih.gov/books/NBK219809/

Osuagwu, U. L., Almaliki, W. H., \& Alanazi, M. (2019). Evaluation of evidence-base practice among eye care practitioners in Saudi Arabia : a cross sectional survey study. Ec Ophthalmology, 10(8), 619-631. https://doi.org/https://www.ecronicon.com/ecop/pdf/ECOP-10-00459.pdf

Rogers, W. A. (2012). Evidence-Based Medicine (R. B. T.-E. of A. E. (Second E. Chadwick, ed.). https://doi.org/https://doi.org/10.1016/B978-0-12-373932-2.00112-5

Straus, S. ., Glasziou, P., Richardson, W. ., \& Haynes, R. . (2019). Evidence-Based Medicine E-Book: How to Practice and Teach EBM (5th ed.). Retrieved from https://books.google.com.my/books?id=BkRPDwAAQBAJ\&lpg=PA1\&pg=PA1\#v=onepage\&q\&f=false

Suttle, C. M., Jalbert, I., \& Alnahedh, T. (2012). Examining the evidence base used by optometrists in Australia and New Zealand. Clinical and Experimental Optometry, 95(1), 28-36. https://doi.org/10.1111/j.1444-0938.2011.00663.x

Vanderbilt, A. ., Jain, S., Mayer, S. D., Gregory, A. ., Ryan, M. ., Bradner, M. ., \& Baugh, R. . (2016). Clinical records organized and optimized for clinical integration and clinical decision making. International Journal of Medical Education, 7, 242-245. https://doi.org/10.5116/ijme.576a.fff 4

Wilson, M. C., Henderson, M. C., \& Gerald, W. S. (2012). Evidence-Based Clinical Decision Making. In The Patient History: An Evidence-Based Approach to Differential Diagnosis (2nd ed.) 